Mathematical Modelling and Analysis

Volume 21 Number 3, May 2016, 430

http://dx.doi.org/10.3846/13926292.2016.1176103

(C) Vilnius Gediminas Technical University, 2016
Publisher: Taylor\&Francis and VGTU

http://www.tandfonline.com/TMMA

ISSN: $1392-6292$

eISSN: $1648-3510$

\title{
Corrigendum
}

\section{Application of the Caputo-Fabrizio Fractional Derivative without Singular Kernel to Korteweg-de Vries-Bergers Equation (http://dx.doi.org/10.3846/13926292.2016.1145607)}

Version of record of article Application of the Caputo-Fabrizio Fractional Derivative without Singular Kernel to Korteweg-de Vries-Bergers Equation by the author Emile Franc Doungmo Goufo, published in the journal Mathematical Modelling and Analysis, 21(2): 188-198 has been updated. The author would like to make following correction: in the title and everywhere in the text Korteweg-de Vries-Bergers should be changed to Korteweg-de Vries-Burgers. 